\title{
FEM Simulation and Analysis of Temperature Field of Environmental Friendly MQL Grinding
}

\author{
P. Patil ${ }^{1^{*}}$, C. Patil ${ }^{2}$ \\ ${ }^{1}$ Abhinav Education Society's College of Engineering and Technology, Pune, India \\ ${ }^{2}$ Professor, Ram Meghe College of Engineering and Management, Amravati, India \\ \{pjpatil76@rediffmail.com\}
}

\begin{abstract}
This study proposes an approach for the development of a three dimensional transient heat conduction finite element model (FEM) for grinding process. FEM simulates the temperature field in conventional and nanofluid based environmental friendly minimum quantity lubrication (MQL) grinding process. For this FEM simulation the boundary conditions were obtained on the basis of results of the heat transfer on semi-infinite object with a heat source moving along its surface. Instrumented surface grinding machine was used for experimental purpose. Lubricant used for MQL system was water based nanofluids of various concentrations. Nanoparticles of $\mathrm{CuO}$ and $\mathrm{Al}_{2} \mathrm{O}_{3}$ were used for preparation of nanofluids. Grinding performance was measured in terms of workpiece surface temperature and cutting force. This model can be used to predict the cooling effectiveness of various lubrication systems. Analysis shows that the FEM temperature values matches with the experimental temperature data.
\end{abstract}

Keywords: Thermal analysis, MQL, Temperature, FEM

\section{Introduction}

Green manufacturing is part of environmentally friendly machining. Environmental, social and economic aspects are considered in in green manufacturing. Cutting fluid contains environmentally harmful chemical constituents. Unhealthy mist generated during machining operation lead to the respiratory diseases. The disposal of untreated used chemical coolant leads to contamination of surface water and ground water. Another objective of environmental conscious machining is reduction in energy consumption. Since all the energy-generating methods creates the environmental pollution in some way. Grinding is a surface finishing process in which close tolerance, good surface finish is achieved. As Compared to other machining processes the grinding process requires high specific energy in material removal due to large surface contact area between workpiece and tool. This results high temperature at the junction of workpiece and grinding wheel. The effect of high temperature causes thermal damage to work piece. Thermal effects in the work piece are in the form of phase transformation, workpiece burn, undesirable residual stress, reduced fatigue strength and cracks (1). To reduce high temperature effects effective lubrication and cooling is required. Coolant lubricates the grinding area, reduce thermal damage to the workpiece and transport the chips away from grinding zone.

Lubrication and cooling of grinding process had studied by many researchers. Large amount of coolant $5400 \mathrm{ml} / \mathrm{hr}$ is utilized by conventional systems. These systems creates unhealthy working environment on the shop floor. Cost of recycling of used coolant is very high. Reduction of grinding fluid is achieved by means of two trends one is minimum quantity lubrication (MQL) and another is dry grinding. In dry grinding method workpiece thermal damage takes place. That's why MQL is better alternative to dry and traditional flood grinding. Advantages of dry and flood grinding are integrated in MQL system. Coolant flow rate in the MQL is $10-100 \mathrm{ml} / \mathrm{hr}$ which is very small in comparison with flood grinding (2). In MQL system cooling function is provided by compressed air and lubrication function is provided by nanofluids of high thermal conductivity. Water based nanoparticles with compressed air was used as a cooling fluid for MQL system. Surface area to volume ratio of nanoparticles is high so that its heat carrying capacity is high (3).

Research on MQL performance for grinding operation indicated that tangential force, normal force, rate of wheel wear was reduced in comparison with convectional cooling. Experimental study on grinding of cast iron by using various nanofluid lubricating mixtures gives positive improvement in surface finish, and $\mathrm{G}$ ratio. [4].

B. Iyer, S. Nalbalwar and R. Pawade (Eds.)

ICCASP/ICMMD-2016. Advances in Intelligent Systems Research.

Vol. 137, Pp. 182-186.

(c) 2017. The authors - Published by Atlantis Press

This is an open access article under the CC BY-NC license (http://creativecommons.org/licens)es/by-nc/4.0/).

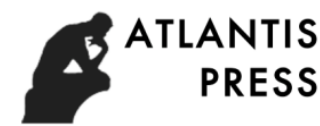


Cong Mao et al had reported MQL grinding is more environmental friendly and economic for AISI 52100 steel [5]. Zhang Dongkun et al had calculated specific grinding energy for dry, flood and MQL grinding conditions [6]. There have been various reported studies proposing both experimental and theoretical aspects of heat transfer in MQL grinding. The classic Jaegers model for thermal analysis for grinding operation assumes that amoving heat source of constant intensity along the surface of semi-infinite body (7).

Outwater and Shaw [8] assumed that the dissipation of grinding energy takes place at the shear plane. In this model the heat transfer to the workpiece was at the shear plane so that some part of heat was conducted into chips and some part in to the workpiece. Significant work reported on heat transfer modeling techniques of grinding application but many lacks in experimental validation due to temperature measuring technique.

Most of the thermal problems in grinding are solved with suitable numerical techniques because they are difficult to solve analytically (9). By use of numerical models, researcher can predict surface temperature of workpiece without performing tedious experiments. Recently finite element method (FEM) has become important tool for predicting the temperature field of surface grinding process (10).

Therefore, the focus of this work is to compare the grinding surface contact temperatures obtained from validated numerical thermal models to the experimental model. The finite element model takes into account the convective cooling of the workpiece. Thermal model will be used for computing temperatures and heat in dry, MQL, and fluid surface grinding.

\section{Analytical thermal modeling of grinding zone}

The major source of heat during grinding is basically from three areas, one from friction between abrasive grain and workpiece, second from friction between abrasive grains and chip, and third from plastic deformation at the shear plane between chip and workpiece. During the MQL grinding heat generated in the grinding zone is transferred into workpiece, grinding wheel, the chip, and the oil mist. In this analysis, it was assumed that heat will be generated at the grinding wheel workpiece interface.

Contact length at the grinding zone (lc) can be calculated from

$l c=(a \cdot d s)^{1 / 2}(1)$

Where $d_{s}$ is the diameter of grinding wheel and a is the depth of cut. Heat flux (q) entering the grinding zone can be calculated from equation 2

$q=\in \frac{F t V s}{l c}(2)$

Where $\epsilon$ is the heat flux percentage entering in to the workpiece, Vs is the grinding wheel speed, Ft tangential force on the workpiece. Heat flux percentage entering in to the workpiece can be calculated from equation 3

$\epsilon=1-\frac{U c h}{U}(3)$

Where Uch is the specific grinding energy required for formation of chips. It is constant for specific workpiece material and its value for all ferrous materials is $13.8 \mathrm{~J} / \mathrm{mm}^{3}$. U is the total specific grinding energy required for grinding the grinding operation and can be calculated from equation 4

$U=\frac{F t V s}{a V w}$

Where $\mathrm{V}_{\mathrm{w}}$ is the speed of the work, $\mathrm{Ft}$ is the tangential force per unit width.

Tangential force can be measured during the testing.

\section{Finite Element Modelling}

\subsection{Geometric Modeling}

The depth of cut affects the temperature field on the workpiece. For finite element simulation the shape of the heat source zone entering to the workpiece is considered to be circular. Method of discretization is used to study the continuous grinding process. It simplifies the FEM modeling. This is performed by 'time step and sub-step' method. In this method a thin material layer is separated after each time step from the workpiece. 
Time step length $t$ is defined as the ratio of the removed workpiece material thickness at each time step to the speed of the worktable.

$$
t=\frac{a}{V w}(5)
$$

It is clear that the accuracy of the simulation increases with the decrease in the length of time step. The simulation takes longer time for smaller length of time step. For higher simulation accuracy, a smaller time step length is necessary.

\subsection{Meshing of Workpiece}

Simulation time depends upon type of the meshing of components. Dense meshing takes larger time for simulation compared to coarse meshing. Temperature gradient is more near the grinding surface. For better accuracy, meshing should be denser in higher temperature gradient zone. At the bottom of the surface temperature gradient is moderate that's why coarser meshing will save the simulation time.

\subsection{Workpiece material properties}

Thermal properties of workpiece material like specific heat, thermal conductivity and density greatly affect the temperature distribution of the grinding zone. Material properties of workpiece had a complicated dependence on temperature. Grinding temperature is a nonlinear function of the heat flux intensity input to the workpiece. Many researchers in past assumed that either workpiece material properties to be constant or linearly proportional to the temperature. Polynomial interpolation method is used to calculate the values of material properties.

\subsection{Boundary conditions}

Heat source moves on the ground surface of workpiece. The boundary conditions are time dependent due to the motion of heat source. At each time step the heat flux boundary condition is loaded on the circular arc surface. This heat flux along circular arc moves to adjunct circular arc at the next time step. For currant time step condition the simulation results of last time step are used. Convection cooling by coolants is another boundary condition. For wet, MQL grinding, the convection coefficient between ground surface, side surface and unground surface and cooling fluid is used. Very minor heat exchange takes place at the bottom surface of workpiece that's why this surface is treated as adiabatic surface.

\section{Experimentation and Measurements}

To test the numerical and analytical results experiments has been conducted on an instrumented surface grinding machine. Lubricant was supplied by MQL system at flow rate of $10 \mathrm{ml} / \mathrm{min}$. Average size abrasives are used for of grinding wheel. The grinding wheel is $150 \mathrm{~mm}$ in diameter and $14 \mathrm{~mm}$ in width. Flat plate of EN8 is used for preparation of Work material. The workpiece material size is $8 \mathrm{~mm}$ in width and $60 \mathrm{~mm}$ in length. Grinding wheel surface speed was set at $30 \mathrm{~m} / \mathrm{s}$ and depth of cut at $10 \mu \mathrm{m}$. The surface grinding operation was performed at the table speed of $2500 \mathrm{~mm} / \mathrm{min}$ in unidirectional way. The dynamometer had recorded the workpiece tangential and normal force of grinding operation. Thermocouple embedded on a workpiece records temperature of grinding zone. Surface roughness of the ground surface was measured by the use of profilometer.

\section{Results and Discussion}

Figure 1 represents three dimensional temperature distribution for dry grinding. The average heat flux to the workpiece during the grinding was $54.43 \mathrm{~W} / \mathrm{mm}^{2}$. Maximum temperature observed during grinding was $604^{\circ} \mathrm{C}$. Figure 2 shows the three dimensional temperature distribution for flood grinding. The average heat flux to the workpiece during the grinding was $37.95 \mathrm{~W} / \mathrm{mm}^{2}$. Maximum temperature observed for flood grinding was $196^{\circ} \mathrm{C}$. Figure 3 indicates the three dimensional temperature distributions for MQL grinding with $6 \% \mathrm{Al}_{2} \mathrm{O}_{3}$ nanofluid coolant. The average heat flux to the workpiece during the grinding was $43.50 \mathrm{~W} / \mathrm{mm}^{2}$. Maximum temperature observed for MQL grinding with $6 \% \quad \mathrm{Al}_{2} \mathrm{O}_{3}$ nanofluid coolant was $414^{\circ} \mathrm{C}$. Maximum temperature observed for MQL grinding with $2 \% \quad \mathrm{Al}_{2} \mathrm{O}_{3}$ and $4 \% \mathrm{Al}_{2} \mathrm{O}_{3}$ nanofluid coolant was $487^{\circ} \mathrm{C}$ and $425^{\circ} \mathrm{C}$. Figure 4 indicates the three dimensional temperature distribution for $\mathrm{MQL}$ grinding with $6 \% \mathrm{CuO}$ nanofluid coolant. The average heat flux to the workpiece during the grinding was $42.27 \mathrm{~W} / \mathrm{mm}^{2}$. Maximum temperature observed for 
MQL grinding with $6 \% \mathrm{CuO}$ nanofluid coolant was $409^{\circ} \mathrm{C}$. Maximum temperature observed for MQL grinding with $2 \% \mathrm{CuO}$ and $4 \% \mathrm{CuO}$ nanofluid coolant was $470^{\circ} \mathrm{C}$ and $425^{\circ} \mathrm{C}$. Figure 5 represents the temperature distribution on the workpiece surface contact for different time steps. At the initial time step workpiece surface temperature is lower and increases as the grinding proceeds. Steady state for transient temperature field was approached after seventh time step. The maximum temperature on workpiece was approached $407^{\circ} \mathrm{C}$ and at a location of $3.2 \mathrm{~mm}$ from the starting edge of grinding. The surface temperature of workpiece remains constant for the remaining length of grinding. Figure 6 indicates the comparison of maximum temperature on workpiece surface for MQL, dry and flood grinding.

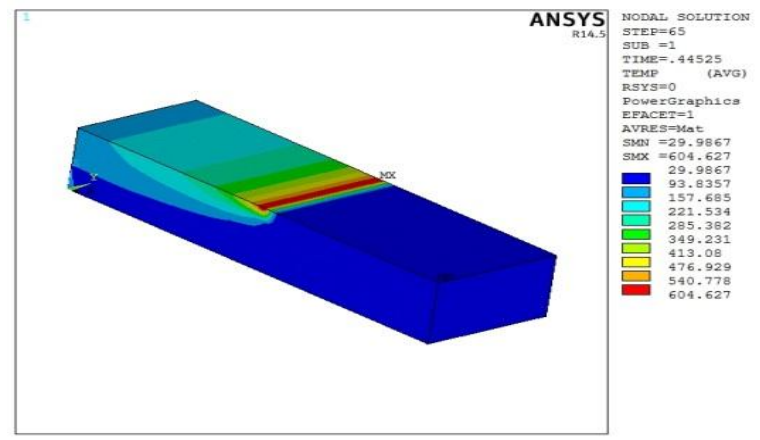

Fig. 1. Temperature field for dry grinding
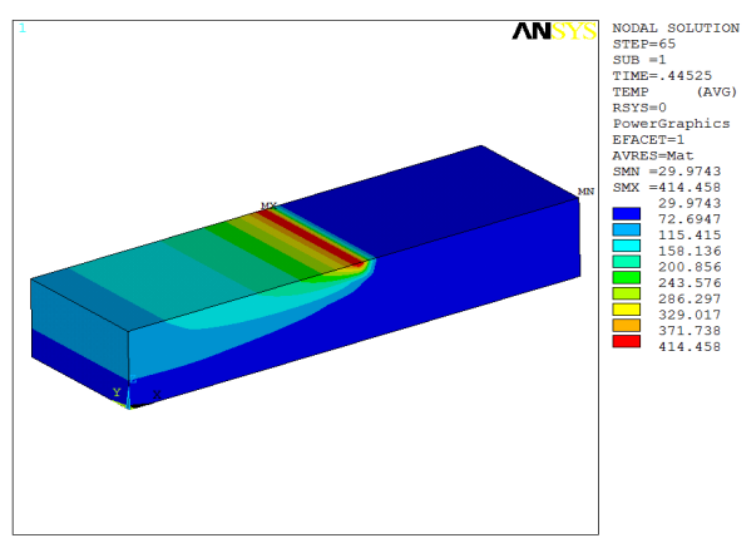

Fig. 3. Temperature field for MQL grindingfor $\mathrm{Al}_{2} \mathrm{O}_{3} 6 \%$ nanofluid

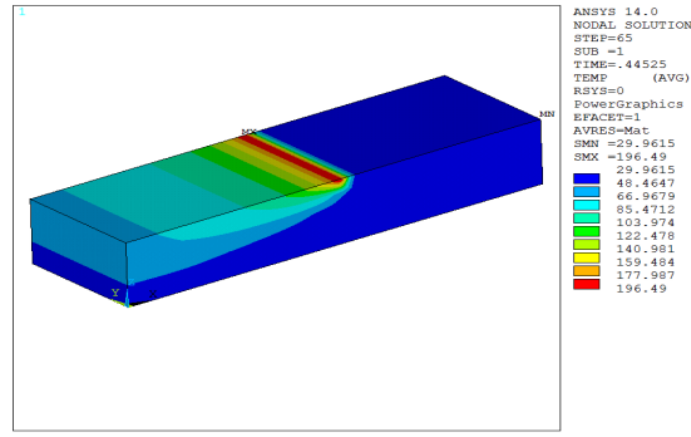

Fig. 2. Temperature field for flood grinding

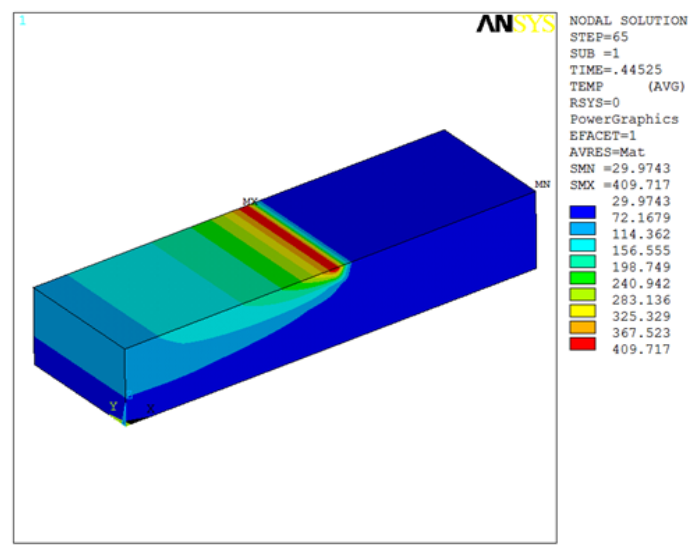

Fig. 4. Temperature field for $\mathrm{MQL}$ grindingfor $\mathrm{CuO}$ $6 \%$ nanofluid

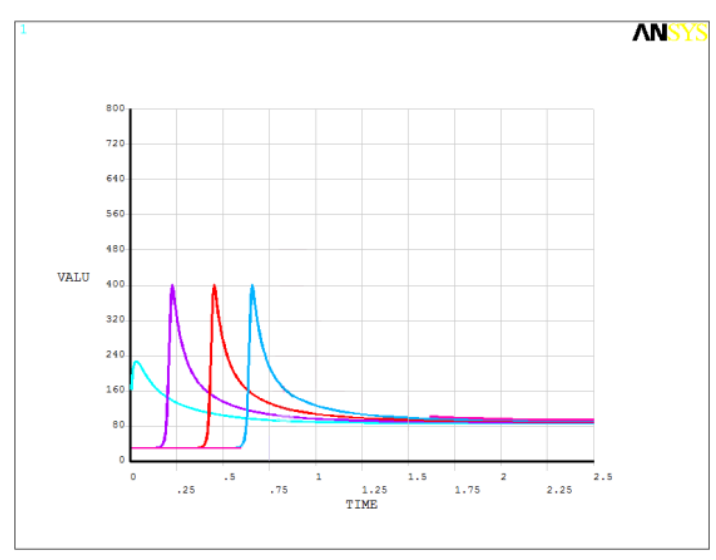

Fig. 5.Temperature field for $M Q L$ grindingMQL for $\mathrm{CuO} 4 \%$ nanofluid

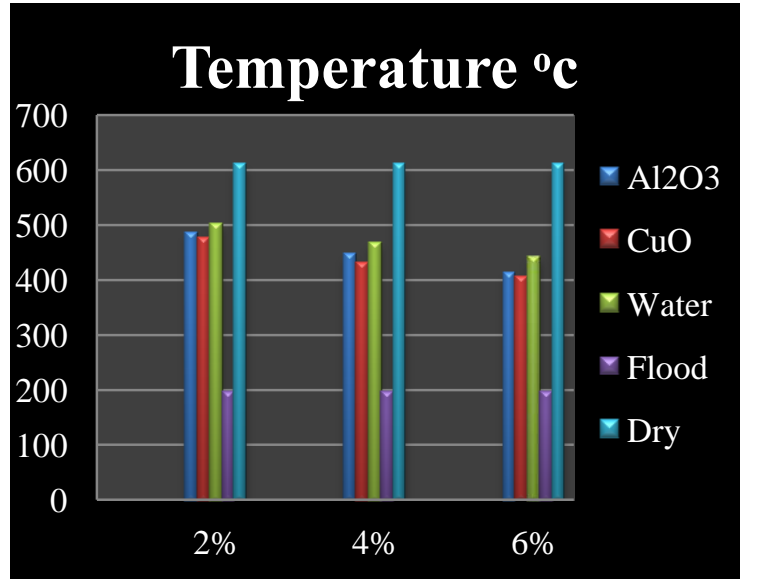

Fig. 6.Maximum Temperature field forgrinding 
It is obvious that highest was observed in dry grinding and it was $604^{\circ} \mathrm{C}$.Flood grinding records minimum temperature of $196^{\circ} \mathrm{C}$. MQL grinding shows better results in comparison with dry grinding. The lowest temperature for MQL grinding was recorded by $\mathrm{CuO} 6 \%$ nanofluids and value was $409^{\circ} \mathrm{C}$.

\section{Conclusions}

Nanofluid based MQL grinding performance was studied and compared with traditional flood and dry grinding processes for the temperature distribution profiles on the workpiece surface. A numerical 3 D Finite element method was used to simulate the temperature of grinding zone. 3 D Finite element model were validated by using experimental data acquired from thermocouple system. Based on the experimental results and theoretical findings, the following conclusions can be drawn

1. In depth understanding of the grinding process can be realized with the finite element model. Steady state for transient temperature field was approached after seventh time step. The maximum temperature on workpiece was at a location of $3.2 \mathrm{~mm}$ from the leading edge of workpiece. The surface temperature of workpiece remains constant for the remaining length of grinding.

2. The average heat flux to the workpiece was $54.43 \mathrm{~W} / \mathrm{mm}^{2}$ for dry grinding, $37.95 \mathrm{~W} / \mathrm{mm}^{2}$ for flood grinding and $42.27 \mathrm{~W} / \mathrm{mm}^{2}$ for $\mathrm{MQL}$ grinding with $6 \% \mathrm{CuO}$ nanofluid coolant. 3. Maximum temperature observed during dry grinding was $604^{\circ} \mathrm{C}$ and for flood grinding was $196^{\circ} \mathrm{C}$.Maximum temperature recorded for $\mathrm{MQL}$ grinding with $6 \% \mathrm{CuO}$ nanofluid coolant was $409^{\circ} \mathrm{C}$. As compared to dry grinding $\mathrm{MQL}$ grinding with $6 \% \mathrm{CuO}$ nanofluid coolant reduces a temperature of workpiece by $195^{\circ} \mathrm{C}$.

4. The experimental investigations indicate that grinding cooling requirements are partly achieved by MQL grinding as compared to flood grinding.

\section{References}

[1]. C. Guo, Y. Wu, V. Varghese, S. Malkin, Temperatures and Energy Partition for Grinding With Vitrified CBN Wheels, CIRP Annals-Manufacturing Technology, Vol. 48, No. 1, pp. 247-250, (1999)

[2]. C. Mao, X. Tang, H. Zou, X. Huang, \& Z. Zhou, Investigation of grinding characteristic using nanofluid minimum quantity lubrication, International Journal of Precision Engineering and Manufacturing, Vol. 13, No. 10, pp. 1745-1752, (2012).

[3]. W.F. Ding, J.H. Xu, Z.Z. Chen, H.H. Su, Y.C. Fu, Grindability and surface integrity of cast nickelbased superalloy in creep feed grinding with brazed CBN abrasive wheel's, Chin J Aeronaut Vol. 23, No. 4, pp. 501-10, (2010).

[4]. L. R. Silva, E. C. Biianchi, R. E. Catai, R. Y. Fusse, Study on the Behaviour of the Minimum Quantity Lubricant-MQL Technique under different Lubricating and cooling conditions when grinding ABNT 4340 Steel, Journal of the Brazilian Society of Mechanical Sciences and Engineering, Vol. 27, No. 2, pp. 192-199, (2005)

[5]. C. Mao, Z.H. Zhou, J. Zhang, X.M. Huang, and D.Y. Gu, An experimental investigation of affected layers formed in grinding of AISI 52100 steel, The International Journal of Advanced Manufacturing Technology, Vol. 54, No. 5-8, pp. 515-523, (2011)

[6]. D. Zhang, C. Li, D. Jia, Y. Zhang, X. Zhang, Specific grinding energy and surface roughness of nanoparticle jet minimum quantity lubrication in grinding, Chinese Journal of Aeronautics, Vol. 28, No. 2, pp. 570-581, (2015)

[7]. Jaeger JC. Moving sources of heat and the temperature at sliding contact. Journal and Proceedings of the Royal Society of New South Wales 76:203-224, (1943)

[8]. Outwater JO, Shaw MC. Surface temperatures in grinding. Trans. ASME;74:73-86, (1952)

[9]. Doman DA, Warkentin A, Bauer R. Finite element modeling approaches in grinding. International Journal of Machine Tools \& Manufacture 49:109-116, (2009).

[10]. Mohammadjafar Hadad, Alireza Sharbati, Thermal aspects of environmentally friendly-MQL grinding process. Procedia CIRP 40, 509-515,(2016). 